\title{
Nano, Ceramic, and Metallic Materials for Energy Application
}

\author{
Ching-Song Jwo, ${ }^{1}$ Ho Chang, ${ }^{2}$ Hong-Ming Lin, ${ }^{3}$ Teobald Kupka, ${ }^{4}$ and Wen-An Chiou ${ }^{5}$ \\ ${ }^{1}$ Emission Reduction \& Energy Conservation Center, National Taipei University of Technology, No. 1, Section 3, \\ Chung-hsiao East Road, Taipei 10608, Taiwan \\ ${ }^{2}$ Graduate Institute of Manufacturing Technology, National Taipei University of Technology, No. 1, Section 3, \\ Chung-hsiao East Road, Taipei 10608, Taiwan \\ ${ }^{3}$ Department of Materials Engineering, Tatung University, No. 40, Section 3, Zhongshan N. Road, Zhongshan District, \\ Taipei City 104, Taiwan \\ ${ }^{4}$ Department of Physical Chemistry and Molecular Modeling, Faculty of Chemistry, University of Opole, Oleska 48, \\ 45-052 Opole, Poland \\ ${ }^{5}$ Center for Nanoscopy and Nanoanalysis, University of Maryland, 1234 Jeong H. Kim Building, College Park, MD 20742-2831, USA
}

Correspondence should be addressed to Ching-Song Jwo; frankjwo@ntut.edu.tw

Received 18 March 2014; Accepted 18 March 2014; Published 15 May 2014

Copyright (C) 2014 Ching-Song Jwo et al. This is an open access article distributed under the Creative Commons Attribution License, which permits unrestricted use, distribution, and reproduction in any medium, provided the original work is properly cited.

Scientists and engineers are interested in comprehending and improving the physical and chemical properties performance of nano-, ceramic, and metallic materials for their applications. This special issue compiles 9 exciting manuscripts, most of which are using nanoparticles and functional nanofluids to improve the performance and efficiency of engineering technology and applications.

The modification of nanoparticles synthesized approaches and applications between multiple engineering technology is addressed in four manuscripts. One interesting topic of nanoparticles in chemical mechanical polishing (CMP) technology to improve the efficacy of polishing steel substrate is addressed by M. J. kao et al. A nanopowder of $\mathrm{SiO}_{2}$ was compounded into polishing slurry for the CMP of steel substrate. Their results indicated the roughness of the steel substrate strongly depends on the size of the abrasive, and the surface roughness decreases as the abrasive size declines. The paper by C. Y. Wu et al. provided a new approach for synthesized centrally hollow microspheres of zinc and employed the permanent floating of zinc particles as flowing anode of zinc-air fuel cell. Their paper provides a detailed performance test of this novel zinc-air fuel cell. $\mathrm{V}$. Loryuenyong et al. described the method to produce titania $\left(\mathrm{TiO}_{2}\right)$ and controlled the porosity and particle size of $\mathrm{TiO}_{2}$ nanoparticles with different quantities of activated carbon. Their results showed that the specific surface area of $\mathrm{TiO}_{2}$ is increased with increasing activated carbon content. Meanwhile, the photocatalytic activity of porous $\mathrm{TiO}_{2}$ and its reduction efficiency are determined by hexavalent chromium $\left(\mathrm{Cr}^{6+}\right)$ reduction rate and optimized ultraviolet illumination, respectively. The paper by $\mathrm{H}$. Zhang et al. studied the effect of $\mathrm{CeO}_{2}$ powders on the defect of $\mathrm{MgO}-\mathrm{CaO}$ refractories. Their results showed the addition of $\mathrm{CeO}_{2}$ increased the lattice constant of $\mathrm{CaO}$, and the bulk density of the samples increased while apparent porosity decreased.

Three of the manuscripts dealing with the ceramics materials, nanoparticles, and numerical stimulation for the energy-savings performance and efficacy are addressed. Enhancing the pool boiling heat transfer efficiency is one of the important methods to solve the high power density system's cooling problems. Since the bubble formation and particle size are two factors related to surface wettability, C.T. Yang and C.-C. Yu deal with the issues with modified aluminum surface with micro/nanoparticles. Vacuum freezedrying technology is applicable to the process of high heatsensitive products. The uniformity and efficiency of heat transfer fluid temperature in shelf are critical concerning improving the quality of high heat-sensitive products. The paper by H.-p. Cheng et al. addressed the issues with the three-dimensional numerical stimulation of the shelf vacuum 
freeze-drying process. The influences of different inlet and outlet positions for shelves on the uniformity of the flow rate and temperature were discussed. Meanwhile, the impacts on the temperature gradient of shelves after heat exchange of different flow rates and low temperature materials are well explored in great depth. The paper by S. Mohammadi explores the phenomenon of polarization fatigue in ferroelectric materials and measures the effect of this phenomenon using PZN-4.5PT single crystal.

Last, two manuscripts addressed the nanofluids applications. M.-J. Kao proposed and developed an arc-submerged nanoparticle synthesis system (ASNSS) for fabricating $\mathrm{Ni} / \mathrm{Ag}$ nanocompound fluid. The detailed properties analysis of the nanocompound fluid was provided. The experiment results showed that the $\mathrm{Ni} / \mathrm{Ag}$ nanofluid not only preserves the magnetic character of the nickel and the ability of silver to absorb visible light but also enhances the thermal conductivity. The paper by T. Y. Chen et al. described the effect of the cationic chitosan dispersant on the thermal conductivity, dispersion, and suspension of $15 \mathrm{~nm} \mathrm{Al}_{2} \mathrm{O}_{3}$ /water nanofluid. The cationic chitosan dispersant was shown to improve the dispersion and suspension of nanofluid. A better performance of thermal conductivity was found when compared with nanofluid when adding cationic chitosan dispersant.

By compiling these papers, we hope to enrich our readers and researchers with respect to these exciting, insightful observations of nano-, ceramic, and metallic materials applications on various engineering. We hope that this special issue would attract major attention of the peers.

\section{Acknowledgments}

We would like to express our appreciation to all the authors and reviewers for their great support to make this special issue possible. 

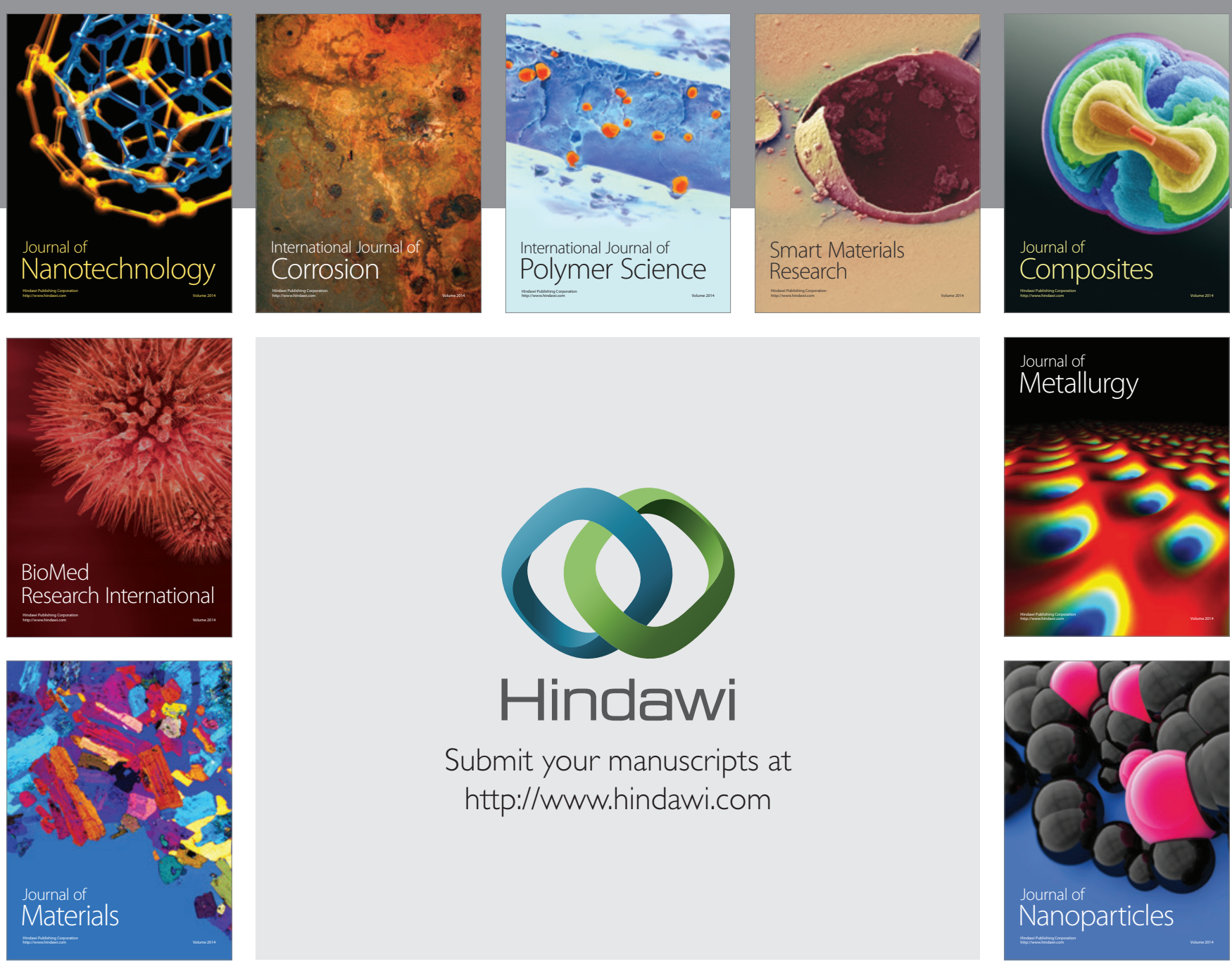

Submit your manuscripts at http://www.hindawi.com
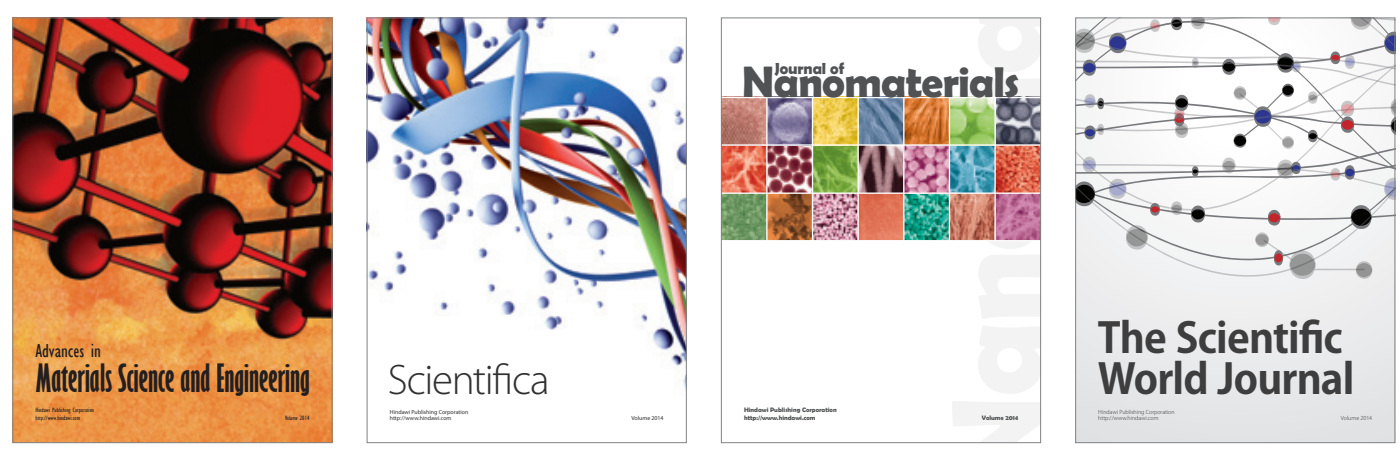

\section{The Scientific World Journal}
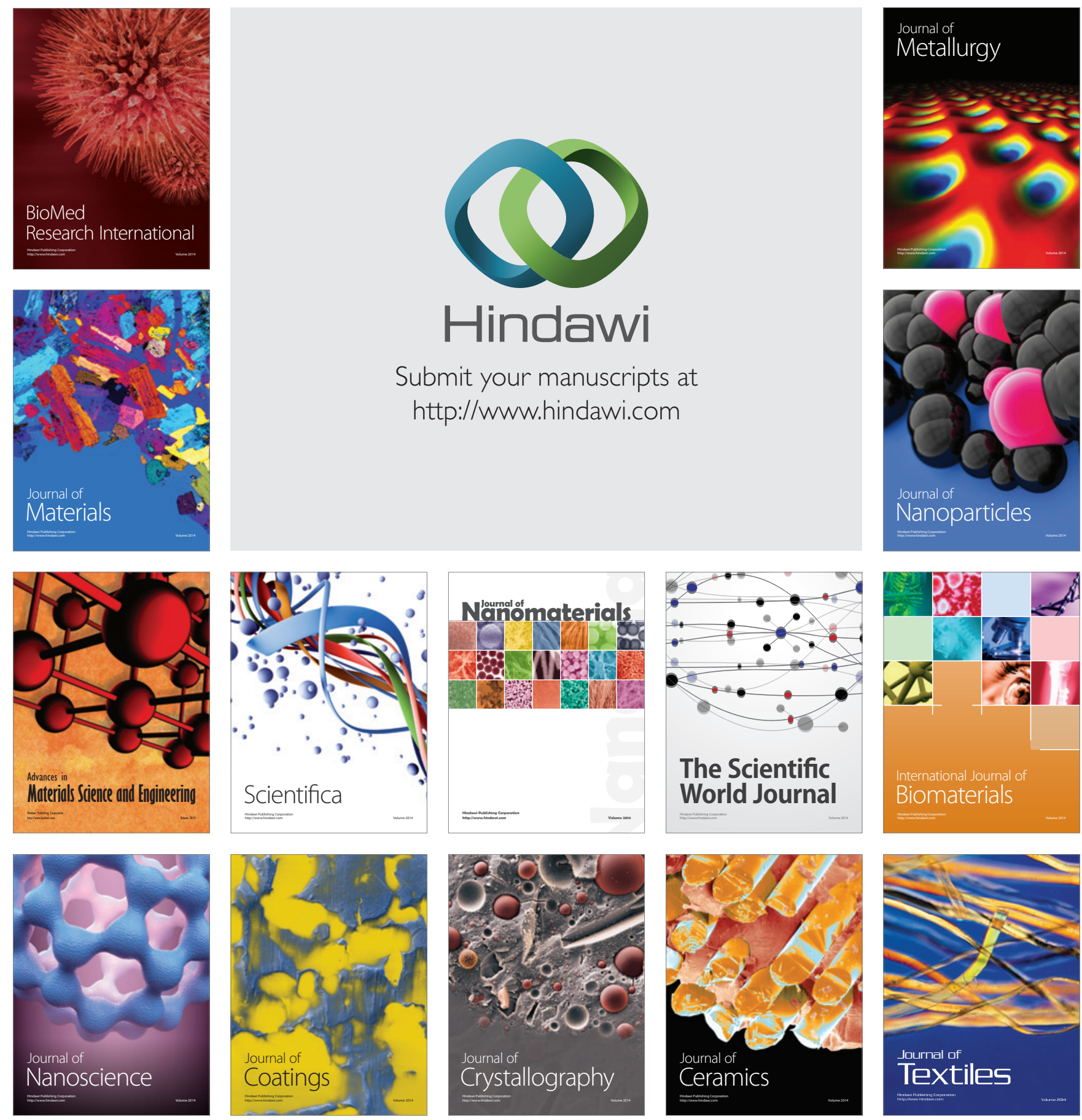